\title{
Incentive to retrogression is what the data suggest after 3 years
}

\author{
Incentivo ao retrocesso é o que os dados sugerem 3 anos após
}

\author{
Valdeci Degiampietro Vaz, ${ }^{1}$ Veralice Maria Gonçalves, ${ }^{1}$ Paulo Belmonte Abreu ${ }^{2}$
}

Dear Editor,

This text has been written to advance the discussion set out in our previous letter entitled "Stimulating retrogression?,"1 published in 2009 in Revista de Psiquiatria do Rio Grande do Sul, former Trends in Psychiatry and Psychotherapy. That letter discussed a risk situation identified at the time, associated with changes in the healthcare payment system, originally based on the actual number of outpatients and level of care intensity and subsequently based on a historical average of payments. At the time, we commented on the risk that lower-complexity or less severe cases would be given preference rather than those patients specifically covered by the legislation applicable to Centers of Psychosocial Care (Centros de Atenção Psicossocial, CAPS), according to which more serious patients should be offered an alternative to hospital care. A warning was made in the sense that, if the shift toward focusing more on patients requiring less intensive care was confirmed, the very guiding principles of the Ministry of Health (Ordinance no. 336/2002) would be disregarded, namely, reserving the CAPS and their three systems of care primarily for patients with mental disorders (Table 1 ).

The original ordinance allowed patients to be transferred from one system of care to another, at a different, higher price according to the complexity of care. Until 2007, the monthly production of the CAPS was controlled by Authorizations for High-Complexity Procedures (Autorização de Procedimentos de Alta Complexidade, APAC), which were used to pay for the procedures carried out and generate statistical data for the Brazilian Ministry of Health. In 2008, the new ordinance that motivated our letter (no. 2867) defined that funds would be calculated according to productivity

Table 1 - Number of Centers of Psychosocial Care (CAPS) and procedures (2007 to 2009)

\begin{tabular}{ll}
\hline System of care & Description \\
\hline Intensive & Severe psychic suffering \\
Semi-intensive & Patients requiring care due to their lack of independence \\
Non-intensive & People who do not require ongoing support to live and carry out their activities \\
Number of CAPS (2007 to 2009) & \\
$\quad$ Brazil & $+40 \%(1,155$ to 1,620$)$ \\
$\quad$ Rio Grande do Sul & $+15.25 \%(118$ to 136$)$ \\
$\quad$ Porto Alegre & $+33 \%(6$ to 8$)$ \\
Number of procedures (2007 to 2009) & $+24.66 \%(5,571,066$ to $6,945,323)$ \\
$\quad$ Brazil & $+38 \%(345,521$ to 438,309$)$ \\
$\quad$ Rio Grande do Sul & $-58 \%(9,506$ to 5,577$)$ \\
$\quad$ Porto Alegre &
\end{tabular}

\footnotetext{
${ }^{1}$ MSc in Medical Sciences: Psychiatry, Universidade Federal do Rio Grande do Sul (UFRGS), Porto Alegre, RS, Brazil. ${ }^{2}$ MD, MHS, PhD. Associate professor of Psychiatry, Faculdade de Medicina, UFRGS.

Financial support: none.

Submitted Jun 24 2012, accepted for publication Jan 03 2013. No conflicts of interest declared concerning the publication of this letter. Suggested citation: Vaz VD, Gonçalves VM, Abreu PB. Incentive to retrogression is what the data suggest after 3 years [letter]. Trends Psychiatry Psychother. $2013 ; 35(1): 85-6$.
} 


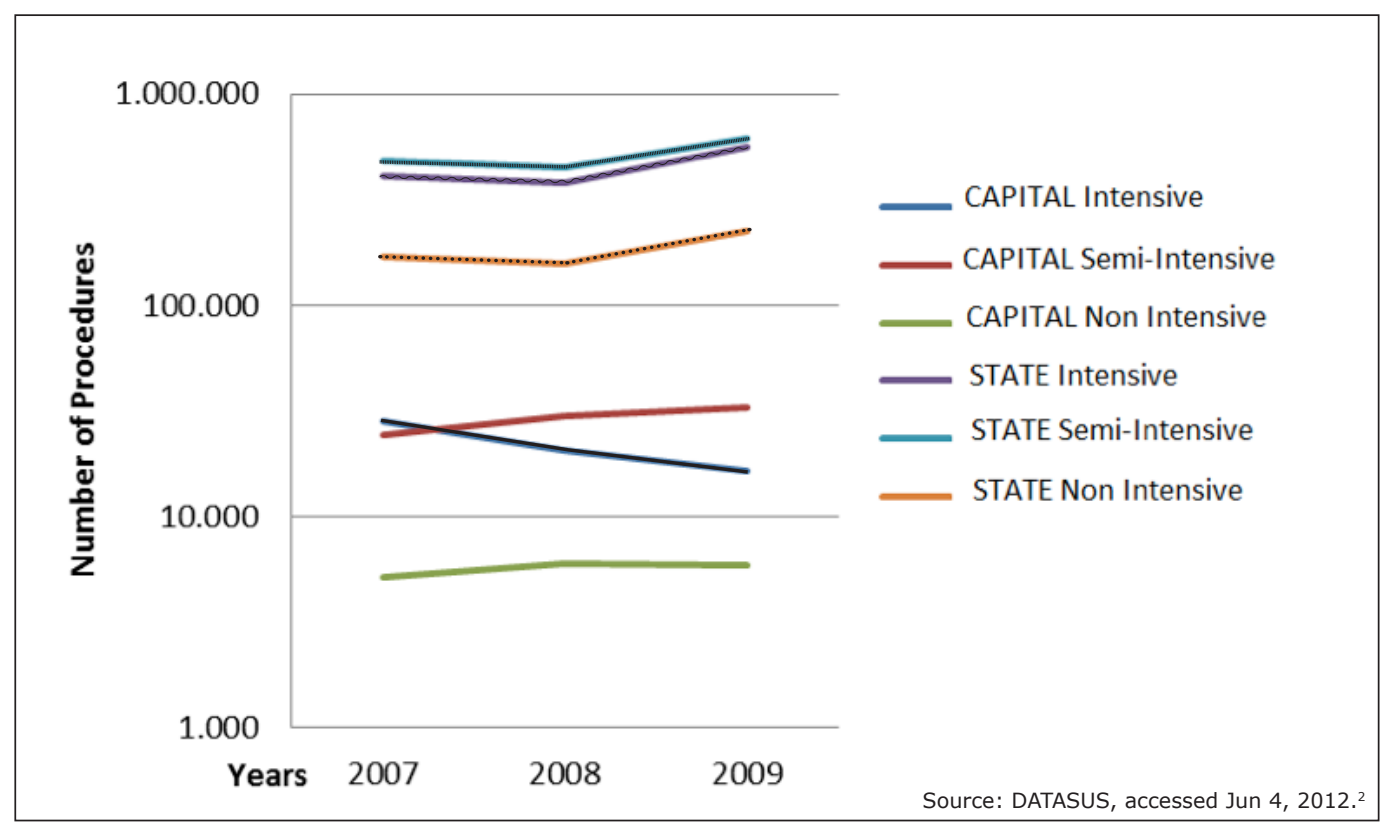

Figure 1 - Number of procedures from 2007 to 2009

or payment data available for April to July 2008, as approved and registered with the Brazilian Unified Health System Outpatient Information Database. The APAC remained as a requirement for service monitoring and assessment and also for fund transfers, but was no longer used for payment purposes. In view of these changes, we surveyed annual data for 2007, 2008, and 2009 generated by the Outpatient Information Database for intensive and semi-intensive adult care, in Brazil, Rio Grande do Sul state, and Porto Alegre (state capital). We found a $40 \%$ increase in the number of CAPS in Brazil, $15.25 \%$ in the state, and a $33 \%$ increase in the state capital Porto Alegre. Also, we found a gross, prorated increase in intensive procedures in the state $(38 \%)$, but a decrease in the capital (58\%), along with a gross, prorated increase in the semi-intensive system, in both Rio Grande do Sul and its capital (Figure 1).

The highlight of this discussion is the scenario that the phenomenon is portraying. Is it possible that the CAPS in the capital have been improving their efficiency and managing to forward patients to less intensive care, while those in the countryside have been less able to find alternative solutions? Or is it that the CAPS in the capital have adopted different criteria for moving patients from intensive to $s$ emi-intensive care? Or has the prediction been fulfilled - the one according to which the CAPS would naturally start handling less complicated cases? This would be due to a lack of control, i.e., due to elimination of the local managers' pressure for increasing productivity, with only the pursuit of higher payment remaining.

In a brief review, we found some scientific studies assessing CAPS, with qualitative and descriptive analyses, but no evaluation of the evolution of procedures in the state or capital. A question therefore remains: where are the evaluations conducted by managers, the ones that would allow us to analyze the movement or migration of one service to another?

\section{References}

1. Saraiva SS, Candiago RH, Gonçalves VM, Abreu PS. Stimulating retrogression? Rev Psiquiatr Rio Gd Sul. 2009;31:132-3.

2. Brazil, Ministry of Health, DATASUS. Produção ambulatorial do SUS - Rio Grande do Sul - por local de atendimento. http://tabnet.datasus.gov.br/cgi/deftohtm.exe?sia/cnv/ qars.def. Accessed 2012 Jun 4.

\section{Correspondence}

Valdeci Degiampietro Vaz

Av. Porto Alegre, 146, Bairro Medianeira

90880-130 - Porto Alegre, RS - Brazil

Tel.: +55-51-3213-2011, +55-51-9968-6225

E-mail:valdeci.vaz@terra.com.br 